\title{
Structure prediction of methyoxy-polybrominated diphenyl ethers (MeO-PBDEs) through GC-MS analysis of their corresponding PBDEs
}

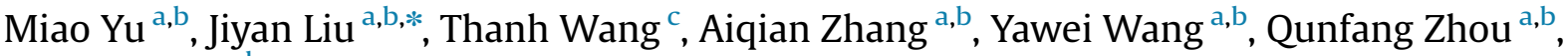 \\ Guibin Jiang a,b \\ a State Key Laboratory of Environmental Chemistry and Ecotoxicology, Research Center for Eco-Environmental Sciences, Chinese Academy of Sciences, P.O. \\ Box 2871, Beijing 100085, China \\ ${ }^{\mathrm{b}}$ College of Resources and Environment, University of Chinese Academy of Sciences, Beijing 100049, China \\ ${ }^{\mathrm{c}}$ MTM Research Centre, School of Science and Technology, Örebro University, Örebro, Sweden
}

\section{A R T I C L E I N F O}

\section{Article history:}

Received 19 November 2015

Received in revised form

18 January 2016

Accepted 23 January 2016

Available online 25 January 2016

Keywords:

PBDEs

MeO-PBDEs

Structure identification

Metabolism

GC-MS

\begin{abstract}
A B S T R A C T
It is hard to quantify the trace pollutants in the environment without the corresponding reference standards. Structure identifications of unknown organic pollutants are thus of great importance in environmental analysis. As for polybrominated diphenyl ethers (PBDE) with one substituent of methoxyl group, there are 837 congeners, but only 32 standards are commercially available. In this work, an effective method based on gas chromatography coupled with mass spectrometry (GC-MS) was proposed to predict the potential structures of methoxylated polybrominated diphenyl ethers (MeO-PBDEs). The mass fragmentation pattern using SIM mode not only provided the useful information on the substitution position of methoxyl group, the number of $\mathrm{Br}$ atoms, but also guaranteed the high sensitivity for trace analysis. Br distribution patterns of the unknown MeO-PBDEs were revealed by a linear regression model with dummy variables which described the retention time relationship between MeO-PBDEs and the corresponding PBDEs on different types of GC columns. This method was successfully used to identify three new MeO-PBDEs metabolites of BDE-28 as 4-MeO-BDE-22, 4'-MeO-BDE-25 and 4-MeO-BDE-31 in the pumpkins. Therefore, the newly developed structure prediction model based on GC-MS behavior is helpful in the evaluation of unknown PBDE metabolites in the environment.
\end{abstract}

(c) 2016 Elsevier B.V. All rights reserved.

\section{Introduction}

As a kind of important bio-transformation products of polybrominated diphenyl ethers (PBDEs) or natural products [1-4], methoxylated PBDEs (MeO-PBDEs) are found in various environmental matrices [5-7] and have drawn considerable attention due to their relatively higher toxicity when compared to the corresponding parent compounds of PBDEs [8-10]. According to the theoretical speculation, there could be $837 \mathrm{MeO}-\mathrm{PBDE}$ congeners with one methoxyl substitution on the diphenyl rings (Fig. 1). However, the number of the reference standards commercially available is less than 40 , which greatly hinder the accurate qualitative analysis of PBDE metabolism in the environment. Meanwhile, MeO-PBDEs levels originated from the biotransformation of PBDEs in environmental samples are always too low to satisfy the

\footnotetext{
* Corresponding author at: State Key Laboratory of Environmental Chemistry and Ecotoxicology, Research Center for Eco-Environmental Sciences, Chinese Academy of Sciences, P.O. Box 2871, Beijing 100085, China.

E-mail address: liujy@rcees.ac.cn (J. Liu).
}

structural identification using NMR or infrared spectroscopy $[11,12]$. Therefore, it is urgent to develop an effective qualitative method for the trace analysis in view of the studies on the environmental fate of PBDEs and MeO-PBDEs.

Gas chromatography-mass spectrometry (GC-MS) is the most popular analytical method for MeO-PBDEs due to their typical fragment ion patterns on MS spectra [13-15]. GC retention behavior provides very important information on the chemical structures as well [16-20]. As indicated recently [12], the COnductor-like Screening MOdel for Realistic Solvents (COMORS) has been successfully used to predict the boiling points of several PBDEs and MeO-PBDEs. The linear correlation between the calculated boiling point and experimental GC retention time was established to identify the structures of MeO-PBDEs (as the derivatives of $\mathrm{OH}-\mathrm{PBDEs}$ ). Also Zenkevich and his colleagues identified hydroxylated metabolites of PCB-9 using GC retention indices [17]. The retention indices of $\mathrm{OH}-\mathrm{PCBs}$ were calculated based on those of PCBs and several OH-PCBs standards using a structurally related additive scheme.

Since the commercial standards are available for all 209 PBDE 


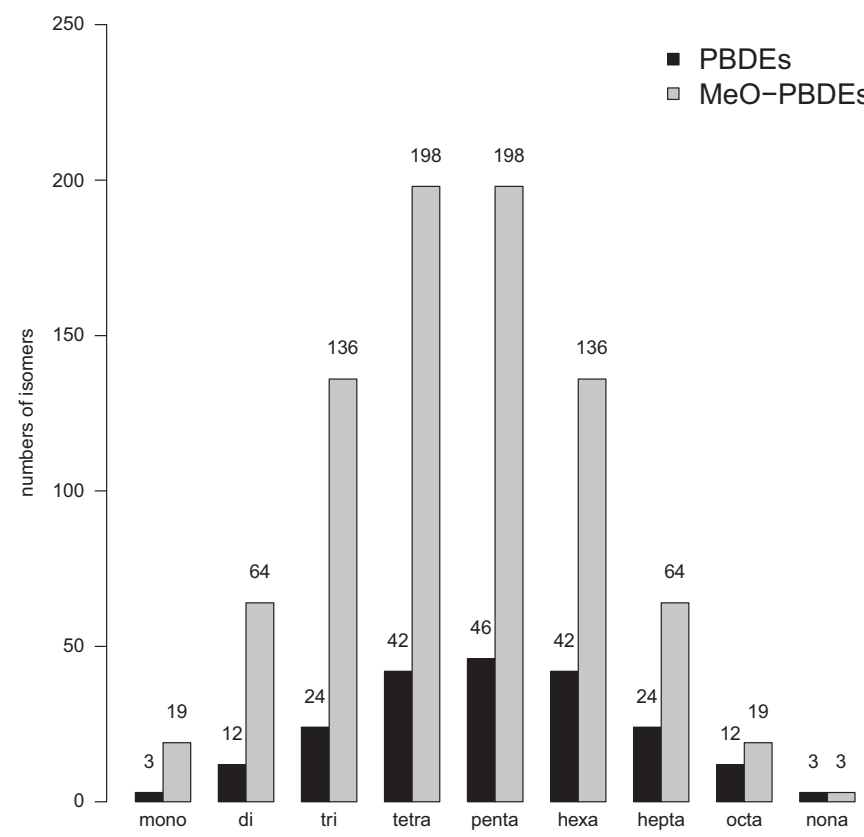

Fig. 1. The theoretical numbers of PBDEs and MeO-PBDEs congeners grouped by bromine atom numbers. The values on the bar show the numbers of the corresponding congeners in each group.

congeners and $\mathrm{Br}$ atom positions in $\mathrm{MeO}-\mathrm{PBDEs}$ is related to their parent PBDEs, we propose a simple regression model with dummy variables rather than density functional theory (DFT) calculation based on GC retention time relationship between MeO-PBDEs and the corresponding PBDEs with the same bromine patterns. This model was successfully used to predict the structures of three unknown MeO-PBDEs metabolites of BDE-28 at trace levels in the pumpkin [4].

\section{Materials and methods}

\subsection{Chemicals}

Thirty-two MeO-PBDEs congeners, their corresponding 26 PBDEs congeners and all other 21 PBDEs congeners with three $\mathrm{Br}$ atoms involved in this study were purchased from AccuStandard (New Haven, CT, USA). More specifically, the stock solutions of PBDEs and MeO-PBDE standards,included BDE-3 (50 $\mu \mathrm{g} / \mathrm{mL}$, purity $>98 \%)$, BDE-7 $(50 \mu \mathrm{g} / \mathrm{mL}$, purity $>97 \%)$ BDE-16 (50 $\mu \mathrm{g} / \mathrm{mL}$, purity $>97 \%)$, BDE-17 $(50 \mu \mathrm{g} / \mathrm{mL}$, purity $>98 \%)$, BDE-18 $(50 \mu \mathrm{g} / \mathrm{mL}$, purity $>98 \%), \quad$ BDE- $19(50 \mu \mathrm{g} / \mathrm{mL}$, purity $>97 \%), \quad$ BDE-20(50 $\mu \mathrm{g} / \mathrm{mL}, \quad$ purity $>99 \%), \quad$ BDE- $21(50 \mu \mathrm{g} / \mathrm{mL}$, purity $>98 \%), \quad$ BDE-22(50 $\mu \mathrm{g} / \mathrm{mL}, \quad$ purity $>99 \%), \quad$ BDE- $23(50 \mu \mathrm{g} / \mathrm{mL}$, purity $>99 \%), \quad$ BDE-24(50 $\mu \mathrm{g} / \mathrm{mL}, \quad$ purity $>99 \%), \quad$ BDE-25(50 $\mu \mathrm{g} / \mathrm{mL}$, purity $>99 \%), \quad$ BDE-26(50 $\mu \mathrm{g} / \mathrm{mL}, \quad$ purity $>97 \%), \quad$ BDE-27(50 $\mu \mathrm{g} / \mathrm{mL}$, purity $>99 \%), \quad$ BDE- $28(50 \mu \mathrm{g} / \mathrm{mL}, \quad$ purity $>99 \%), \quad$ BDE- $29(50 \mu \mathrm{g} / \mathrm{mL}$, purity $>98 \%), \quad$ BDE-30 $(50 \mu \mathrm{g} / \mathrm{mL}, \quad$ purity $>98 \%), \quad$ BDE-31 $(50 \mu \mathrm{g} / \mathrm{mL}$, purity $>98 \%), \quad$ BDE-32(50 $\mu \mathrm{g} / \mathrm{mL}, \quad$ purity $>98 \%), \quad$ BDE-33 $(50 \mu \mathrm{g} / \mathrm{mL}$, purity $>98 \%), \quad$ BDE-34(50 $\mu \mathrm{g} / \mathrm{mL}, \quad$ purity $>99 \%), \quad$ BDE-35(50 $\mu \mathrm{g} / \mathrm{mL}$, purity $>99 \%), \quad$ BDE-36(50 $\mu \mathrm{g} / \mathrm{mL}, \quad$ purity $>97 \%), \quad$ BDE-37 $(50 \mu \mathrm{g} / \mathrm{mL}$, purity $>97 \%), \quad$ BDE-38(50 $\mu \mathrm{g} / \mathrm{mL}, \quad$ purity $>99 \%), \quad$ BDE-39 $(50 \mu \mathrm{g} / \mathrm{mL}$, purity $>99 \%), \quad$ BDE- $42(50 \mu \mathrm{g} / \mathrm{mL}, \quad$ purity $>98 \%), \quad$ BDE- $47(50 \mu \mathrm{g} / \mathrm{mL}$, purity $>97 \%), \quad$ BDE- $49(50 \mu \mathrm{g} / \mathrm{mL}, \quad$ purity $>99 \%), \quad$ BDE-68 $(50 \mu \mathrm{g} / \mathrm{mL}$, purity $>99 \%), \quad$ BDE-75(50 $\mu \mathrm{g} / \mathrm{mL}, \quad$ purity $>99 \%), \quad$ BDE- $82(50 \mu \mathrm{g} / \mathrm{mL}$, purity $>98 \%), \quad$ BDE- $85(50 \mu \mathrm{g} / \mathrm{mL}, \quad$ purity $>99 \%), \quad$ BDE- $87(50 \mu \mathrm{g} / \mathrm{mL}$, purity $>99 \%), \quad$ BDE-90(50 $\mu \mathrm{g} / \mathrm{mL}, \quad$ purity $>98 \%), \quad$ BDE-99(50 $\mu \mathrm{g} / \mathrm{mL}$, purity $>99 \%), \quad$ BDE-100(50 $\mu \mathrm{g} / \mathrm{mL}, \quad$ purity $>98 \%), \quad$ BDE- $101(50 \mu \mathrm{g} / \mathrm{mL}$, purity $>98 \%), \quad$ BDE-137(50 $\mu \mathrm{g} / \mathrm{mL}$, purity $>98 \%), \quad$ BDE- $140(50 \mu \mathrm{g} / \mathrm{mL}$, purity $>98 \%$ ), BDE-154(50 $\mu \mathrm{g} / \mathrm{mL}$, purity $>99 \%)$, BDE- $157(50 \mu \mathrm{g} / \mathrm{mL}$, purity $>97 \%), \quad$ BDE- $180(50 \mu \mathrm{g} / \mathrm{mL}, \quad$ purity $>99 \%), \quad$ BDE- $182(50 \mu \mathrm{g} / \mathrm{mL}$, purity $>99 \%$, BDE- $187(50 \mu \mathrm{g} / \mathrm{mL}$, purity $>99 \%), \quad$ BDE- $188(50 \mu \mathrm{g} / \mathrm{mL}$, purity $>97 \%), \quad$ BDE-201 $(50 \mu \mathrm{g} / \mathrm{mL}, \quad$ purity $>99 \%), \quad 2 '-\mathrm{MeO}-\mathrm{BDE}-3$ $(50 \mu \mathrm{g} / \mathrm{mL}$, purity $>99 \%), 2^{\prime}-\mathrm{MeO}-\mathrm{BDE}-7(10 \mu \mathrm{g} / \mathrm{mL}$, purity $>98 \%), 3^{\prime}-$ MeO-BDE-7(50 $\mu \mathrm{g} / \mathrm{mL}, \quad$ purity $>99 \%), \quad 4^{\prime}-\mathrm{MeO}-\mathrm{BDE}-17(50 \mu \mathrm{g} / \mathrm{mL}$, purity $>99 \%$ ), 5'-MeO-BDE-25(50 $\mu \mathrm{g} / \mathrm{mL}$, purity $>98 \%$ ), 2'-MeO-BDE$28(10 \mu \mathrm{g} / \mathrm{mL}$, purity $>99 \%)$, 3'-MeO-BDE-28(50 $\mu \mathrm{g} / \mathrm{mL}$, purity $>99 \%)$, 4-MeO-BDE-42(10 $\mu \mathrm{g} / \mathrm{mL}$, purity $>99 \%)$, 3-MeO-BDE-47(50 $\mu \mathrm{g} / \mathrm{mL}$, purity $>99 \%$ ), 5-MeO-BDE-47(50 $\mu \mathrm{g} / \mathrm{mL}$, purity $>99 \%$ ), 6-MeO-BDE-47 $(10 \mu \mathrm{g} / \mathrm{mL}$, purity $>99 \%), \quad 4^{\prime}-\mathrm{MeO}-\mathrm{BDE}-49(10 \mu \mathrm{g} / \mathrm{mL}$, purity $>99 \%)$, 2'-MeO-BDE-68(10 $\mu \mathrm{g} / \mathrm{mL}, \quad$ purity $>99 \%), \quad$ 2'-MeO-BDE-75(50 $\mu \mathrm{g} / \mathrm{mL}$, purity $>97 \%$ ), 6-MeO-BDE-82(10 $\mu \mathrm{g} / \mathrm{mL}$, purity $>98 \%$ ), 6-MeO-BDE-85 $(10 \mu \mathrm{g} / \mathrm{mL}$, purity $>99 \%)$, 6-MeO-BDE- $87(10 \mu \mathrm{g} / \mathrm{mL}$, purity $>98 \%)$, 4-MeO-BDE-90(10 $\mu \mathrm{g} / \mathrm{mL}$, purity $>99 \%), \quad$ 5'-MeO-BDE- $99(10 \mu \mathrm{g} / \mathrm{mL}$, purity $>99 \%$ ), 6'-MeO-BDE-99(10 $\mu \mathrm{g} / \mathrm{mL}$, purity $>99 \%)$, 3-MeO-BDE$100(50 \mu \mathrm{g} / \mathrm{mL}$, purity $>99 \%), 5^{\prime}-\mathrm{MeO}-\mathrm{BDE}-100(10 \mu \mathrm{g} / \mathrm{mL}$, purity $>99 \%)$, 4-MeO-BDE-101(50 $\mu \mathrm{g} / \mathrm{mL}$, purity $>98 \%)$, 6-MeO-BDE-137(10 $\mu \mathrm{g} / \mathrm{mL}$, purity $>99 \%$ ), 6-MeO-BDE-140(10 $\mu \mathrm{g} / \mathrm{mL}$, purity $>97 \%)$, 3'-MeO-BDE$154(10 \mu \mathrm{g} / \mathrm{mL}$, purity $>98 \%), 6-\mathrm{MeO}-\mathrm{BDE}-157(10 \mu \mathrm{g} / \mathrm{mL}$, purity $>97 \%)$, 6-MeO-BDE-180(50 $\mu \mathrm{g} / \mathrm{mL}$, purity $>98 \%)$, 6-MeO-BDE- $182(10 \mu \mathrm{g} / \mathrm{mL}$, purity $>97 \%), \quad 4-\mathrm{MeO}-\mathrm{BDE}-187(50 \mu \mathrm{g} / \mathrm{mL}, \quad$ purity $>97 \%), \quad 4-\mathrm{MeO}-$ BDE- $188(50 \mu \mathrm{g} / \mathrm{mL}$, purity $>99 \%)$ and $4^{\prime}-\mathrm{MeO}-\mathrm{BDE}-201(50 \mu \mathrm{g} / \mathrm{mL}$, purity $>98 \%$ ). Fig. S1, S2 and S3 in the supplementary material depict the molecular structures of these tested compounds. The standards were transferred into CERTAN capillary vials from ampoules as the stock solutions. The working solutions were prepared by the solvent displacement from isooctane or methanol to hexane and the subsequent gradual dilution to $1 \mu \mathrm{g} / \mathrm{mL}$.

\subsection{Exposure of pumpkin to BDE-28}

In vivo hydroponic exposure of pumpkin to BDE-28 and the sample pretreatment procedures were the same as the protocols described in our previous study [4]. In brief, pumpkin (Cucurbita

Table 1

The qualitative ions of MeO-BDEs in SIM mode.

\begin{tabular}{|c|c|c|c|c|c|}
\hline \multirow[t]{2}{*}{ Compounds } & \multirow[t]{2}{*}{ Formula } & \multicolumn{4}{|l|}{ Selected ions } \\
\hline & & {$[\mathrm{M}]^{+}$} & {$[\mathrm{M}-2 \mathrm{Br}]^{+}$} & {$\left[\mathrm{M}-\mathrm{BrCH}_{3}\right]^{+}$} & {$\left[\mathrm{M}-\mathrm{CH}_{3}\right]^{+}$} \\
\hline MeO-mono-BDE & $\mathrm{C}_{13} \mathrm{H}_{11} \mathrm{O}_{2} \mathrm{Br}$ & $278 / 280^{\mathrm{a}}$ & - & 184 & $263 / 265$ \\
\hline MeO-di-BDE & $\mathrm{C}_{13} \mathrm{H}_{10} \mathrm{O}_{2} \mathrm{Br}_{2}$ & $355.9 / 359.9$ & 198 & $262 / 264$ & 342.9 \\
\hline MeO-tri-BDE & $\mathrm{C}_{13} \mathrm{H}_{9} \mathrm{O}_{2} \mathrm{Br}_{3}$ & $435.8 / 437.8$ & $276 / 278$ & 341.9 & $420.8 / 422.8$ \\
\hline MeO-tetra-BDE & $\mathrm{C}_{13} \mathrm{H}_{8} \mathrm{O}_{2} \mathrm{Br}_{4}$ & $513.7 / 517.7$ & 355.9 & $419.8 / 421.8$ & 500.7 \\
\hline MeO-penta-BDE & $\mathrm{C}_{13} \mathrm{H}_{7} \mathrm{O}_{2} \mathrm{Br}_{5}$ & $593.6 / 595.6$ & $433.8 / 435.8$ & 499.7 & $578.6 / 580.6$ \\
\hline MeO-hexa-BDE & $\mathrm{C}_{13} \mathrm{H}_{6} \mathrm{O}_{2} \mathrm{Br}_{6}$ & $671.5 / 675.5$ & 513.7 & 577.6/579.6 & 658.5 \\
\hline MeO-hepta-BDE & $\mathrm{C}_{13} \mathrm{H}_{5} \mathrm{O}_{2} \mathrm{Br}_{7}$ & $751.5 / 753.4$ & $591.6 / 593.6$ & 657.5 & $736.4 / 738.4$ \\
\hline MeO-octa-BDE & $\mathrm{C}_{13} \mathrm{H}_{4} \mathrm{O}_{2} \mathrm{Br}_{8}$ & $829.4 / 833.4$ & 671.5 & $735.4 / 737.4$ & 816.3 \\
\hline MeO-nona-BDE & $\mathrm{C}_{13} \mathrm{H}_{3} \mathrm{O}_{2} \mathrm{Br}_{9}$ & $909.3 / 911.3$ & $749.4 / 751.4$ & 815.3 & $894.2 / 896.2$ \\
\hline
\end{tabular}

\footnotetext{
a The peak area ratios of the selected molecular/fragment isotopic pairs are around 1:1.
} 
Table 2

Experimental retention times (RTs), predicted RTs and their 95\% prediction intervals of MeO-PBDEs and the corresponding PBDEs on DB-5 ms and DB-17 ms.

\begin{tabular}{|c|c|c|c|c|c|c|c|c|c|}
\hline \multirow[t]{2}{*}{ Names } & \multirow[t]{2}{*}{ MeO-position } & \multicolumn{4}{|c|}{ DB-5 ms } & \multicolumn{4}{|c|}{ DB-17 ms } \\
\hline & & RT & PBDE's RT $^{\mathrm{a}}(\mathrm{min})$ & Predicted $\mathrm{RT}^{\mathrm{b}}$ (min) & $95 \%$ prediction interval $^{c}(\mathrm{~min})$ & RT & PBDE's RT ${ }^{\mathrm{a}}(\mathrm{min})$ & Predicted $\mathrm{RT}^{\mathrm{b}}(\mathrm{min})$ & $95 \%$ prediction interval $^{\mathrm{C}}(\mathrm{min})$ \\
\hline 2'-MeO-BDE-3 & ortho & 9.379 & 7.608 & 5.792 & {$[3.772,7.812]$} & 11.112 & 8.165 & 5.514 & {$[2.752,8.277]$} \\
\hline 2'-MeO-BDE-7 & Ortho & 12.837 & 9.978 & 9.263 & {$[7.275,11.251]$} & 16.571 & 11.72 & 11.159 & {$[8.462,13.855]$} \\
\hline 3-MeO-BDE-7 & Meta & 13.868 & 9.978 & 8.508 & {$[6.525,10.491]$} & 17.64 & 11.72 & 10.255 & {$[7.575,12.936]$} \\
\hline $2^{\prime}$-MeO-BDE-28 & Ortho & 19.63 & 15.519 & 16.081 & {$[14.143,18.019]$} & 25.995 & 19.618 & 20.902 & {$[18.291,23.514]$} \\
\hline 5'-MeO-BDE-25 & Meta & 20.234 & 14.840 & 14.898 & {$[12.945,16.850]$} & 25.839 & 18.630 & 18.733 & {$[16.103,21.363]$} \\
\hline 4'-MeO-BDE-17 & Para & 20.913 & 14.623 & 14.436 & {$[12.418,16.453]$} & 27.354 & 18.998 & 18.308 & {$[15.593,21.023]$} \\
\hline 3'-MeO-BDE-28 & Meta & 21.074 & 15.519 & 15.741 & {$[13.791,17.691]$} & 27.926 & 19.618 & 20.891 & {$[18.268,23.513]$} \\
\hline 2'-MeO-BDE-75 & Ortho & 24.622 & 20.088 & 21.092 & {$[19.177,23.006]$} & 32.536 & 25.779 & 27.665 & {$[25.091,30.240]$} \\
\hline 2'-MeO-BDE-68 & Ortho & 24.697 & 20.727 & 21.167 & {$[19.252,23.081]$} & 30.983 & 25.904 & 26.060 & {$[23.478,28.641]$} \\
\hline 6-MeO-BDE-47 & Ortho & 25.648 & 21.753 & 22.121 & {$[20.210,24.033]$} & 33.739 & 28.197 & 28.909 & {$[26.339,31.480]$} \\
\hline 3-MeO-BDE-47 & Meta & 27.092 & 21.753 & 21.781 & {$[19.842,23.721]$} & 35.136 & 28.197 & 28.345 & {$[25.736,30.955]$} \\
\hline 5-MeO-BDE-47 & Meta & 27.575 & 21.753 & 22.266 & {$[20.326,24.206]$} & 35.883 & 28.197 & 29.118 & {$[26.508,31.727]$} \\
\hline 4'-MeO-BDE-49 & Para & 27.988 & 20.656 & 21.537 & {$[19.562,23.512]$} & 36.231 & 26.621 & 27.487 & {$[24.823,30.150]$} \\
\hline 4-MeO-BDE-42 & Para & 31.083 & 22.926 & 24.643 & {$[22.680,26.607]$} & 40.938 & 29.5 & 32.353 & {$[29.703,35.003]$} \\
\hline 5'-MeO-BDE-100 & Meta & 31.843 & 27.324 & 26.550 & {$[24.606,28.494]$} & 41.082 & 35.128 & 34.493 & {$[31.876,37.110]$} \\
\hline 6'-MeO-BDE-99 & Ortho & 32.628 & 29.291 & 29.127 & {$[27.227,31.028]$} & 41.845 & 37.161 & 37.290 & {$[34.734,39.847]$} \\
\hline 3-MeO-BDE-100 & Meta & 32.794 & 27.324 & 27.505 & {$[25.559,29.450]$} & 41.523 & 35.128 & 34.949 & {$[32.331,37.568]$} \\
\hline 6-MeO-BDE-87 & Ortho & 34.047 & 31.068 & 30.552 & {$[28.650,32.453]$} & 44.319 & 40.125 & 39.848 & {$[37.289,42.408]$} \\
\hline 4-MeO-BDE-90 & Para & 35.038 & 29.125 & 28.613 & {$[26.659,30.567]$} & 44.088 & 36.993 & 35.610 & {$[32.964,38.257]$} \\
\hline 5'-MeO-BDE-99 & Meta & 35.038 & 29.291 & 29.757 & {$[27.805,31.709]$} & 44.147 & 37.161 & 37.662 & {$[35.035,40.290]$} \\
\hline 4'-MeO-BDE-101 & Para & 35.476 & 27.943 & 29.053 & {$[27.099,31.006]$} & 44.562 & 35.169 & 36.100 & {$[33.454,38.747]$} \\
\hline 6-MeO-BDE-85 & Ortho & 36.346 & 32.517 & 32.859 & {$[30.955,34.763]$} & 46.872 & 42.129 & 42.488 & [39.924,45.052] \\
\hline 6-MeO-BDE-82 & Ortho & 37.655 & 33.891 & 34.173 & {$[32.266,36.080]$} & 48.375 & 43.602 & 44.042 & {$[41.473,46.611]$} \\
\hline 3'-MeO-BDE-154 & Meta & 40.236 & 34.198 & 34.974 & {$[32.999,36.949]$} & 48.729 & 43.067 & 42.400 & {$[39.749,45.050]$} \\
\hline 6-MeO-BDE-140 & Ortho & 42.506 & 38.51 & 39.042 & {$[37.118,40.966]$} & 52.684 & 49.167 & 48.497 & {$[45.910,51.085]$} \\
\hline 6-MeO-BDE-137 & Ortho & 43.095 & 39.366 & 39.633 & {$[37.707,41.560]$} & 53.7 & 50.528 & 49.548 & {$[46.955,52.141]$} \\
\hline 6-MeO-BDE-157 & Ortho & 45.711 & 41.137 & 42.259 & {$[40.318,44.200]$} & 57.381 & 53.329 & 53.354 & {$[50.737,55.971]$} \\
\hline 4-MeO-BDE-188 & Para & 47.583 & 42.169 & 41.205 & {$[39.233,43.177]$} & 59.627 & 53.064 & 51.677 & {$[48.981,54.373]$} \\
\hline 6-MeO-BDE-182 & Ortho & 48.474 & 45.057 & 45.032 & {$[43.073,46.991]$} & 61.38 & 56.165 & 57.489 & {$[54.838,60.139]$} \\
\hline 4-MeO-BDE-187 & Para & 49.264 & 43.89 & 42.892 & {$[40.912,44.872]$} & 60.809 & 54.089 & 52.899 & {$[50.195,55.600]$} \\
\hline 6-MeO-BDE-180 & Ortho & 49.591 & 47.835 & 46.153 & {$[44.186,48.121]$} & 61.45 & 58.738 & 57.561 & {$[54.910,60.212]$} \\
\hline $4^{\prime}-\mathrm{MeO}-\mathrm{BDE}-201$ & Para & 57.753 & 52.459 & 51.412 & {$[49.376,53.449]$} & NA & NA & $\mathrm{NA}$ & NA \\
\hline
\end{tabular}

a PBDE refers to the corresponding PBDE which have the same Br patterns as MeO-PBDE

${ }^{\text {b }}$ Predicted RT refers to the calculated RT of the corresponding PBDE by the model.

' 95\% prediction interval of the calculated RT, the candidate PBDEs' RTs should be in this interval. 
Table 3

Regression coefficients and statistical descriptors of the GC-RT regression model: $\mathrm{RT}_{\mathrm{BDE}-n}=\beta_{0} \mathrm{RT}$ MeO-BDE- $n+\beta_{1} D_{\text {ortho }}+\beta_{2} D_{\text {meta }}+\beta_{3} D_{\text {para }}$

\begin{tabular}{|c|c|c|c|c|c|c|c|c|}
\hline Column & $\beta_{0}$ & $\beta_{1}$ & $\beta_{2}$ & $\beta_{3}$ & $N$ & $r^{2}$ & $F$ & $\mathrm{SE}^{a}$ \\
\hline DB-5 ms & 1.0037 & -3.6219 & -5.4112 & -6.5549 & 32 & 0.9992 & 8994 & 0.8984 \\
\hline DB-17 ms & 1.0339 & -5.9750 & -7.9833 & -9.9743 & $31^{\mathrm{b}}$ & 0.9991 & 7249 & 1.207 \\
\hline
\end{tabular}

a Standard error, square root of the variance of the residuals.

b $4^{\prime}-\mathrm{MeO}-\mathrm{BDE}-201$ was undetectable.

Table 4

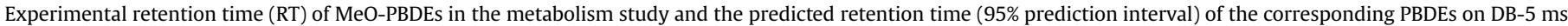
and DB-17 ms.

\begin{tabular}{|c|c|c|c|c|c|c|}
\hline \multirow[t]{2}{*}{ Metabolites } & \multicolumn{3}{|l|}{ DB-5 ms } & \multicolumn{3}{|l|}{ DB-17 ms } \\
\hline & $\mathrm{RT}(\min )$ & Candidate PBDEs RT a & 95\% Prediction interval $(\min )^{b}$ & $\mathrm{RT}(\min )$ & Candidate PBDEs RT & 95\% Prediction interval ( $\mathrm{min}$ ) \\
\hline MeO-BDE-A & 21.794 & 15.320 & {$[13.309,17.331]$} & 27.305 & 18.258 & {$[15.542,20.973]$} \\
\hline MeO-BDE-B & 22.377 & 15.905 & {$[13.898,17.912]$} & 28.299 & 19.285 & {$[16.577,21.993]$} \\
\hline MeO-BDE-C & 23.479 & 17.011 & {$[15.012,19.011]$} & 31.443 & 22.536 & {$[19.849,25.223]$} \\
\hline
\end{tabular}

a The calculated RT of the corresponding PBDEs by the model.

b $95 \%$ prediction interval of the calculated RT of the corresponding PBDEs by the model.

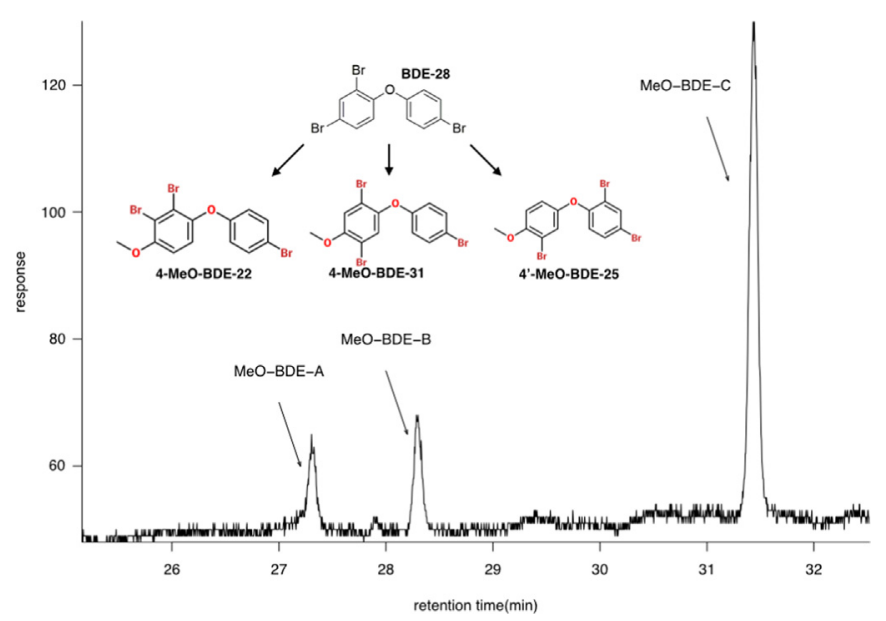

Fig. 2. GC-MS chromatograms of three metabolites on DB-17 ms in SIM mode $(\mathrm{m} /$ $z=436$ ) and their potential structures.

maxima $\times$ Cucurbita moschata) seedlings were pre-germinated to around $5 \mathrm{~cm}$ in height, then hydroponically exposed to $100 \mathrm{ng} / \mathrm{mL}$ BDE-28 for 10 days. The plant samples were freeze dried and stored at $-20{ }^{\circ} \mathrm{C}$ before analysis. The pretreatment procedures included extraction by hexane, purification by florisil column and elution with $20 \mathrm{~mL}$ of DCM / hexane $(1: 1, \mathrm{v} / \mathrm{v})$. The eluates were dried and re-dissolved in $0.1 \mathrm{~mL}$ of hexane before GC analysis for MeO-PBDEs.

\subsection{Instrumental analysis}

PBDEs and MeO-PBDEs were analyzed on Agilent 6890 GC coupled with 5973 C MS detector (Agilent Technologies, Palo Alto, CA). A volume of $2 \mu \mathrm{L}$ of $1 \mu \mathrm{g} / \mathrm{mL}$ standards or $2 \mu \mathrm{L}$ of the samples were injected into GC inlet (7683B Series Injector) at $280{ }^{\circ} \mathrm{C}$ in the splitless mode. DB-5 ms column ( $30 \mathrm{~m} \times 0.25 \mathrm{~mm} \times 0.25 \mu \mathrm{m}$, J \& W Scientific, Folsom, CA) and DB-17 ms column (30 $\mathrm{m} \times 0.25 \mathrm{~mm} \times 0.25 \mu \mathrm{m}, \mathrm{J} \&$ W Scientific, Folsom, CA) were used for chromatographic separation. Helium, as the carrier gas, was controlled at a constant flow of $1.0 \mathrm{~mL} / \mathrm{min}$. The oven program was started at the initial temperature of $90^{\circ} \mathrm{C}$ for $2 \mathrm{~min}$, then increased to $200^{\circ} \mathrm{C}$ at $30^{\circ} \mathrm{C} / \mathrm{min}$, then to $300{ }^{\circ} \mathrm{C}$ at $2{ }^{\circ} \mathrm{C} / \mathrm{min}$. The post run was set at $320^{\circ} \mathrm{C}$ and held for 3 min. Both full scan $(m / z 100-1000)$ and SIM modes were performed under EI mode in mass spectrometer and the retention times
(RTs) of all analytical standards were recorded for data analysis. The fragment ions monitored in SIM are shown in Table 1.

\subsection{Statistic analysis}

The data analysis was performed under R 3.1.3 [21]. Paried t-test was used to test the difference of retention time between $\mathrm{MeO}$ PBDEs and corresponding PBDEs and the significance level is 0.05 . The linear regression analysis with dummy variables was performed to get the parameters for the model and lack-of-fit test was performed at the significance level 0.05 for the model linearity.

\section{Results and discussion}

\subsection{Trace analysis of potential MeO-PBDEs}

According to the full scan mass spectra of the available standards, MeO-PBDEs generally have prominent $\mathrm{Br}$ isotopic distribution around the molecular ions $\left([\mathrm{M}]^{+}\right)$. Those $[\mathrm{M}]^{+}$revealed the numbers of $\mathrm{Br}$ atoms in the corresponding MeO-PBDEs. The isotopic ratio of $[\mathrm{M}]^{+}$peaks (around 1, Table 1 ) was used for further qualitative analysis. The monitoring of $[\mathrm{M}]^{+}$peaks is suitable for trace analysis of potential MeO-PBDEs in environmental samples[11].

Meanwhile, PBDE metabolites with different methoxyl substitution positions showed different mass spectrum profiles in EI mode (see Fig. S4) [13-15,22]. Thus, feature fragment ions could be used to further identify the potential positions of methoxyl groups in MeO-PBDEs. Specifically, $[\mathrm{M}]^{+}$and $\left[\mathrm{M}-\mathrm{CH}_{3}\right]^{+}$were used for the characterization of $p$-MeO-PBDEs. $[\mathrm{M}]^{+}$and $\left[\mathrm{M}-\mathrm{BrCH}_{3}\right]^{+}$were monitored to characterize $o$-substituted MeO-PBDEs and $m$-MeOPBDEs was identified based on $[\mathrm{M}]^{+}$alone (see Table 1). Accordingly, the analysis of molecular ions and featured ions of $\mathrm{MeO}$ PBDEs in SIM mode could help to screen trace levels of MeOPBDEs in the environment and clarify methoxyl position of the metabolites.

\subsection{Br atom position in phenyl rings}

We performed paired $t$-test analysis for the retention time differences between MeO-PBDEs and their corresponding PBDEs. Results showed the $p$-values were all below 0.05 , showing the differences are significant. Fig. S5 also shows that the differences 
of retention times ( $\Delta$ RTs, as shown in Eq. (1)) between PBDEs and the corresponding $\mathrm{MeO}-\mathrm{PBDEs}$ with the same pattern of $\mathrm{Br}$ atoms are mainly related to methoxyl group substitution

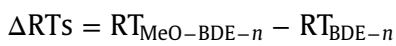

in which, $n$ is the congener number of PBDE and the corresponding MeO-PBDE. $\triangle$ RTs obtained from both DB-5 ms and DB17 ms columns showed similar trend, that was, $\Delta$ RT increased in the order of $o-<m-<p-$. Therefore, with the information on methoxyl substitution, the retention time differences between PBDEs and MeO-PBDEs could be modeled by a linear regression with dummy variables as shown in the following Eq. (2):

$\mathrm{RT}_{\mathrm{BDE}-n}=\beta_{0} \mathrm{RT}_{\mathrm{MeO}-\mathrm{BDE}-n}+\beta_{1} D_{\text {ortho }}+\beta_{2} D_{\text {meta }}+\beta_{3} D_{\text {para }}$

The dummy variable in regression could be treated as the categorical variable. General linear regression used continuous variables and dummy variable could extend the scope of regression models from continuous variables to the mixture of continuous and categorical variables. In this study, the dummy variables ( $D_{\text {ortho, }} D_{\text {meta }}$ and $\left.D_{\text {para }}\right)$ could only take the value 0 or 1 to indicate the position of methoxyl group. For example, when the mass spectrum of a certain MeO-PBDE showed a potential $p$ substitution of methoxyl group, $D_{\text {ortho }}$ and $D_{\text {meta }}$ would be 0 and $D_{\text {para }}$ would be 1 . The final model was optimized and built based on GC-MS behaviors of all tested PBDEs and MeO-PBDEs standards. The parameter of $\beta$ was calculated by the regression analysis according to the experimental RTs of MeO-PBDEs and the corresponding PBDEs shown in Table 2. The regression coefficients and statistical descriptors are listed in Table 3. Also we performed lack-of-fit test for the linearity of our model and results showed that there was not enough evidence at the 0.05 level to conclude lack of linear fit existed in our model. The coefficients of determination $\left(r^{2}\right)$ on both columns were higher than 0.999 , showing this model could well explain and capture most of the variances in the retention time relationship between MeO-PBDEs and the corresponding PBDEs. This high correlation also indicated the elution order of the compounds in the chromatographic columns and the retention time values of PBDEs could be used to characterize $\mathrm{Br}$ patterns in the corresponding MeO-PBDEs.

More specifically, when the retention times of unknown MeOPBDEs and the positions of methoxyl groups were obtained on GCMS as shown in the first part, $95 \%$ prediction intervals of the corresponding PBDEs' retention times could be calculated by the model described above. All PBDEs congeners eluted in that intervals might show the same $\mathrm{Br}$ atom substitution pattern as the unknown MeO-PBDE. Also by overlapping the predicted ranges of candidate PBDEs, additional different columns, e.g. DB-17 ms column could provide complementary selectivity for this method. In addition, when certain structures of MeO-PBDEs were clarified by some metabolism pathways reported in previous study [12], the elution order of PBDEs could be directly used to get the Br profiles in MeO-PBDEs based on the high correlation in the model proposed herein.

\section{Application in BDE-28 metabolism study}

In our former study on the pumpkin (C. maxima $\times$ C. moschata) exposed to BDE-28 [4], three unknown MeO-PBDE metabolites were found and identified as para- substituted MeO-triBDEs using GC-MS in SIM mode. Therefore, the dummy variable linear regression for these three compounds was Eq. (3):

$\mathrm{RT}_{\mathrm{BDE}-n}=\beta_{0} \mathrm{RT}_{\mathrm{MeO}-\mathrm{BDE}-1}+\beta_{3} D_{\mathrm{para}}$

According to the parameters and the uncertainty shown in
Table 3, the range of the candidate PBDEs for MeO-BDE-A, - $\mathrm{B}$, - $\mathrm{C}$ on DB-5 $\mathrm{ms}$ and DB-17 ms columns are shown in Table 4. The potential $\mathrm{Br}$ patterns of unknown MeO-PBDEs might be the same as those of PBDEs occurring in the intersection of prediction intervals on two columns. Take MeO-BDE-C as an example, two columns narrowed down the candidate number of the corresponding PBDEs from 24 to 7 . The analysis on more columns with different stationary phases might further narrow down the number of the candidates.

The metabolic pathway was also considered. Similar to the metabolism of BDE-47 in the pumpkin, which was through $\mathrm{NIH}$ shift, these MeO-triBDE metabolites of BDE-28 might come from direct NIH shift on BDE-28 or be transformed from the corresponding $\mathrm{OH}$-triBDE originated from $\mathrm{NIH}$ shift $[3,23]$. Thus the para-MeO-PBDE metabolites could only be 4-MeO-BDE-22, 4'$\mathrm{MeO}-\mathrm{BDE}-25$ and 4-MeO-BDE-31. The retention times of the corresponding BDE-25, 31 and 22 were 14.840, 14.961 and 16.727 on DB-5 ms column and 18.630, 18.687 and 21.134 on DB-17 ms column, respectively (Fig. 2). According to the model, the elution order of MeO-PBDEs should be the same as that of those three PBDEs. As a validation, the retention times of the corresponding PBDEs were also in the predicted intervals as evaluated by the model. Accordingly, the compounds of MeO-tri-BDE-A, MeO-triBDE-B and MeO-tri-BDE-C were identified as 4'-MeO-BDE-25, 4-MeO-BDE-31 and 4-MeO-BDE-22, respectively.

In summary, we established a novel method to predict the structures of unknown MeO-PBDEs based on GC-MS behaviors of the compounds themselves and the corresponding PBDE standards. In the case study of the pumpkin hydroponically exposed to BDE-28, this method was successfully applied to identify MeOPBDE metabolites. As OH-PBDEs are closely related with the formation of MeO-PBDEs in the environment, this newly developed method is attractive in the prediction of the unknown structures of OH-PBDEs at trace levels. Meanwhile, this method is very promising to be applied for the structural characterization of some other congeners like MeO-PCBs which lack of commercial standards.

\section{Acknowledgment}

This work was jointly supported by the National Basic Research Program of China (No. 2014CB441105), the National Natural Science Foundation of China (Nos. 21277153 and 21177147), the Strategic Priority Research Program of the Chinese Academy of Sciences (No. XDB14010400). We thanked Dr. Shanjun Song, National Institute of Metrology, China for his kind help on the instrumental analysis.

\section{Appendix A. Supplementary material}

Supplementary data associated with this article can be found in the online version at http://dx.doi.org/10.1016/j.talanta.2016.01.047.

\section{References}

[1] X. Qiu, M. Mercado-Feliciano, R.M. Bigsby, R.A. Hites, Environ. Health Perspect. 115 (2007) 1052-1058.

[2] H.M. Stapleton, S.M. Kelly, R. Pei, R.J. Letcher, C. Gunsch, Environ. Health Perspect. 117 (2009) 197-202.

[3] J. Sun, J. Liu, M. Yu, C. Wang, Y. Sun, A. Zhang, T. Wang, Z. Lei, G. Jiang, Environ. Sci. Technol. 47 (2013) 3701-3707.

[4] M. Yu, J. Liu, T. Wang, J. Sun, R. Liu, G. Jiang, Environ. Sci. Technol. 47 (2013) 13494-13501.

[5] A. Pettersson, B. van Bavel, M. Engwall, B. Jimenez, Arch. Environ. Contam. Toxicol. 47 (2004) 542-550. 
[6] S.B. Wiseman, Y. Wan, H. Chang, X. Zhang, M. Hecker, P.D. Jones, J.P. Giesy, Mar. Pollut. Bull. 63 (2011) 179-188.

[7] J. Sun, J. Liu, Y. Liu, G. Jiang, Environ. Pollut. 176 (2013) 100-105.

[8] G. Su, J. Xia, H. Liu, M.H. Lam, H. Yu, J.P. Giesy, X. Zhang, Environ. Sci. Technol. 46 (2012) 10781-10788.

[9] X.M. Ren, L.H. Guo, Environ. Sci. Process. Impacts 15 (2013) 702-708.

[10] H. Liu, S. Tang, X. Zheng, Y. Zhu, Z. Ma, C. Liu, M. Hecker, D.M. Saunders, J. P. Giesy, X. Zhang, H. Yu, Environ. Sci. Technol. 49 (2015) 1823-1833.

[11] F.J. Santos, M.T. Galceran, J. Chrimatogr. A 1000 (2003) 125-151.

[12] S. Simpson, M.S. Gross, J.R. Olson, E. Zurek, D.S. Aga, Anal. Chem. 87 (2015) 2299-2305.

[13] M. Athanasiadou, G. Marsh, I. Athanassiadis, L. Asplund, A. Bergman, J. Mass Spectrom. 41 (2006) 790-801.

[14] R.A. Hites, Environ. Sci. Technol. 42 (2008) 2243-2252.

[15] Y.J. Yu, L. Mao, L.M. Hon-Wah, H.X. Yu, Chin. J. Anal. Chem. 36 (2008) 1029-1034.
[16] V.S. Ong, R.A. Hites, Anal. Chem. 63 (1991) 2829-2834.

[17] I.G. Zenkevich, M. Moeder, G. Koeller, S. Schrader, J. Chrimatogr. A 1025 (2004) 227-236.

[18] Y. Wang, A. Li, H. Liu, Q. Zhang, W. Ma, W. Song, G. Jiang, J. Chromatogr. A 1103 (2006) 314-328

[19] P. Korytar, A. Covaci, J. de Boer, A. Gelbin, U.A. Brinkman, J. Chromatogr. A 1065 (2005) 239-249.

[20] H. Wei, R. Yang, A. Li, E.R. Christensen, K.J. Rockne, J. Chromatogr. A 1217 (2010) 2964-2972.

[21] R. Core Team, R Foundation for Statistical Computing, Vienna, Austria, 2015.

[22] Y. Sun, G. Ren, S. Ma, K. Zheng, Z. Yu, M. Wu, G. Sheng, J. Fu, Chemosphere 92 (2013) 286-292.

[23] J. Sun, J. Liu, Y. Liu, M. Yu, G. Jiang, Environ. Sci. Technol. Lett. 1 (2014) 236-241. 